\title{
The gradation impact of glass material on combined with copper
}

\author{
Izabela Wilkos ${ }^{1, *}$, Marcin Jędrzak ${ }^{2}$, and Marek Szymczak ${ }^{1}$ \\ ${ }^{1}$ UTP University of Science and Technology, Faculty of Mechanical Engineering, Department of \\ Biomedical Engineering, Al. prof. S. Kaliskiego 7, 85-796 Bydgoszcz, Poland
}

\begin{abstract}
The results of observation on the impact of the glass baking process on the quality of connection with glass drenched in copper. The aim of the work is to present the results obtained in the process of fragmentation of the glass and the assessment of the particle size distribution on the durability of the connection of glass and copper. The test used two types of glass divided by different fineness. Copper was used in the form of galvanized sheet metal and pipes and cables to diversify cross-section openness. Received samples were cut with a circular saw in accordance with vertical and horizontal axis. Microscopic analysis, allowing to evaluate porosity of obtained composite, was carried out. On the basis of the analysis of the results, it was specified that fineness of glass and the temperature of the baking process has a significant influence on the combination of glass with copper.
\end{abstract}

\section{Introduction}

Among all available and created materials, glass seems to be the most unusual. Until the 18th century, glass had great significance for the development of civilization and culture. "Glass has made it possible to see new worlds, brought them together and revealed" [1]. Also nowadays glass is a material that through continuous development of technology is present and shapes our nearest environment very strongly. Large glass plane buildings open and combine spaces, and small everyday items made of glass complement and organize interiors. Each material has unique characteristics assigned only to itself. Glass is a solid, however, its appearance is more similar to the liquid. During production it can be ironed, pulled, rolled, blown and extruded and later cut, engraved, stippled, flatten and grinded. The smelting process and subsequent treatment of obtained glass gives a lot of room for new experiences and research. Quartz glass has a high melting point and permeability of light rays. Thanks to its significant resistance to temperature variations it can be combined with other materials. There is something magical about glass. Ingredients are mixed in the right proportions and new results are formed. In order to achieve an artistic vision, glass requires the creator to master complex technology [2]. After concrete, glass is the most commonly used material in architecture. It does not occur only as a filling of window openings, but also as an exterior wall cladding of the building as well as in its interior. Raw, cold concrete is covered with coloured planes of glass and light sources hidden behind cause the spaces to breathe and

*Corresponding author: wilkos.izabela@gmail.com 
become friendly to mankind. The new building of the Szczecin Philharmonic is an excellent example of the application of the glass on the façade in order to give a unique character to the block blended in the structure of the closest surroundings. The building, due to its function is devoid of windows and frosted glass surfaces resemble a huge block [3]. Trend to use glass is also more visible in interiors. It is used in the interiors exposed to moisture and also as glass balustrades, stairs, walls, furniture and wall panels. Illuminated panels give the ability to create a unique atmosphere and affect the homeowner [4]. Light and its colour have a definite effect on human health. "The human eye distinguishes 256 colours, while there are 16 million in the world. All colours are recorded by the human brain which then sends a specified stimulus to other organs like the thyroid gland, testes, ovaries or pancreas. The glands produce hormones directly affecting the behaviour of the human body" [5]. Colour therapy not only heals, but also increases the immunity and has a definite impact on the recovery of people's vitals. Therefore, creation of new technology associated with the process of creating glass is so important. As a result, the formed material has new light transmission properties, filters them and can have additional parameters affecting the human body. The author of the article [6] used in his research two types of glass, for this purpose he used a blend with a specific chemical composition and glass aggregate from waste, which had already undergone the baking process. The author has shown influence of content of the chemical glass composition on its strength. Adding cullet to the recycled glass gave the strengthening effect of the baked material for compression. Compressive strength significantly increased in the case of waste glass additives with the least amount of fragmentation. In the article [7], authors analysed the effect of grain size of glass in combination with self-compacting concrete. Experiments have shown the significant impact of shredded glass increasing the mechanical strength of the resulting composite. It can be concluded from research carried out that glass with an appropriate granularity allows you to modify the modern materials while improving their physico-chemical properties. Article [8] provides an overview of the physical and chemical properties of glass and its use in combination with the building materials. The size of glass particles has a very large effect on mechanical strength and elasticity. Depending on the size of the glass granulate compressive, bending and stretching strength changes as well as modulus of elasticity. Density changes of glass components after the burn process were noted. The author of the article [9] provides in his research the temperature variation of heat treatment. Lowering and raising the temperature of the heated glass to yield influenced the appearance of cracks in the material. Glass with a high content of metals, which underwent three-point and four-point bending was used in the research. Application of burn temperature in the range of $750^{\circ} \mathrm{C}-850^{\circ} \mathrm{C}$ allowed the author of the article [10] to carry out thermal and structural analysis and glass bioactivity. Low burning glass temperature raises the bioactivity of the material. Increasing the process temperature causes a noticeable increase in glass crystallinity material and its chemical stabilisation. This analysis allows you to expand the observation of specific physico-chemical changes in the material and easier adaptation to expected effects of carried out tests. In the article [11], the authors also study the durability of the connection in relation to advanced materials, ceramics, and it turns out that the higher the temperature, the lower the medium's adhesion and the joint loses its mechanical properties.

The aim of the article is to improve the process of joining various types of glass with copper alloys. Authors made an analysis of the effect of granulation on the baking temperature. Microscopic examinations were done to check the structure of the obtained composite.

\section{Methods and materials}

In order to obtain samples the preparation process has been divided into relevant stages: breaking of the glass, sifting, grain size measurement, processing copper elements, burning, cutting, and taking microscopic photos of baked structure. To the division of cullet vibratory sieve shaker Analysette 3, Fritsch brand, was used as well as stainless steel 
analytical $200 / 50 \mathrm{~mm}$ sieves, Fritsch brand, which is a classic sieve shaker in which an electromagnetic drive causes the sieves to oscillate in a vertical direction. The material is sieved periodically, propelled upward off the sieve fabric and if it fits into the sieve mesh then it falls down to the collector. Dry sieving is done in measurement range: $32 \mu \mathrm{m}-63 \mathrm{~mm}$, maximum sample quantity is approx. $1 \mathrm{~kg}$, and sifting time: $3-10 \mathrm{~min}$. The measurement in accordance with ISO 9001:2000. Designation is done with a multi-sieve classifier choosing a set of sieves appropriate to the particles dimension range. A few to several sieves are usually used, depending on the required accuracy of the analysis. After sieving samples of the mixture each sieve residue is weighed and shown as a percentage (relative to the initial sample weight). The first stage of crushed grains of glass sample testing was the analysis of the size and shape of particles using digital image processing (CAMSIZER). In the second stage of glass sample a stereomicroscope OPTA-TECH SN series with high resolution digital camera has been used.

The heat treatment process used a solid ceramic chamber furnace SNOL 4/1200, which scope of work goes up to $1,200^{\circ} \mathrm{C}$ and has a ceramic chamber with mechanical ventilation. The whole furnace is controlled electronically which allows for detailed planning of the burning process in terms of time and temperature. Ready samples were subjected to cutting process. For this purpose, table band saw Proxxon Micromot MBS 240/E 27172 was used along with a diamond coating suitable for cutting glass in the presence of water. After full process of samples burning, an analysis of all tests using a stereo microscope OPTA-TECH SN series with high resolution digital camera with OptaView software. Two types of glass were used to carry out research, different in terms of chemical composition. Popular industrial soda-lime glass and crystal glass were used due to the aesthetic qualities and strength. The chemical composition of the used glass cullet is presented in table 1 .

Table 1. Chemical composition of pressed industrial glass and crystal glass used in tests [12].

\begin{tabular}{lccccccccc}
\hline Type of glass & $\mathrm{SiO}_{2}$ & $\mathrm{Al}_{2} \mathrm{O}_{3}$ & $\mathrm{Fe}_{2} \mathbf{O}_{3}$ & $\mathbf{P b O}$ & $\mathbf{M g O}$ & $\mathbf{B a O}$ & $\mathbf{C a O}$ & $\mathbf{N a}_{2} \mathbf{O}$ & $\mathbf{K}_{2} \mathbf{O}$ \\
\hline Pressed industrial glass & 76.0 & 0.8 & 0.05 & - & 0.1 & 0.65 & 7.2 & 13.5 & 1.3 \\
\hline Crystal glass & 58.16 & 0.29 & 0.015 & 24.55 & - & - & 0.05 & 2.70 & 14.5 \\
\hline
\end{tabular}

Dissected copper sheet, a pipe and copper wire with protective coating were used to carry out the tests. A diverse cross section of metal elements was used in order to check the impact of cutting of the test connection. Received samples were divided into four groups: 1-soda-lime 0-1 mm crushing, 2-crystal glass 0-1 mm crushing, 3-soda-lime 1-10 mm crushing, 4-crystal glass $1-10 \mathrm{~mm}$ crushing.

\section{The results}

One of the most important features of the bulk material is its particle size composition which is the quantitative distribution of the grains of the material in terms of their size. Grain size is determined by linear dimensions: length, width and thickness, measured in two planes mutually perpendicular to each other. Grain tests results are presented on drawings Fig. 1. and Fig. 2. The highest degree of granularity was samples no. 1 (soda-lime) and no. 2 (crystal glass). As a slightly better fragmented we can consider sample no. 2 marked on charts with a dotted line. Similarly, the situation was for dust particles content their largest number also been reported for samples 1 and 2 (no. 1 had the maximum number of about 300,000 dusty particles). Sample no. 4 (crystal glass) shows the lowest degree of fragmentation and the minimum content of dust particles (about 15,000) out of all the analysed samples. A large similarity of the distribution process is also visible in samples 1 and 2 (the most crushed - continuous and dotted line on the charts) and samples 3 and 4 (worst crushed- marked by dashed lines). 


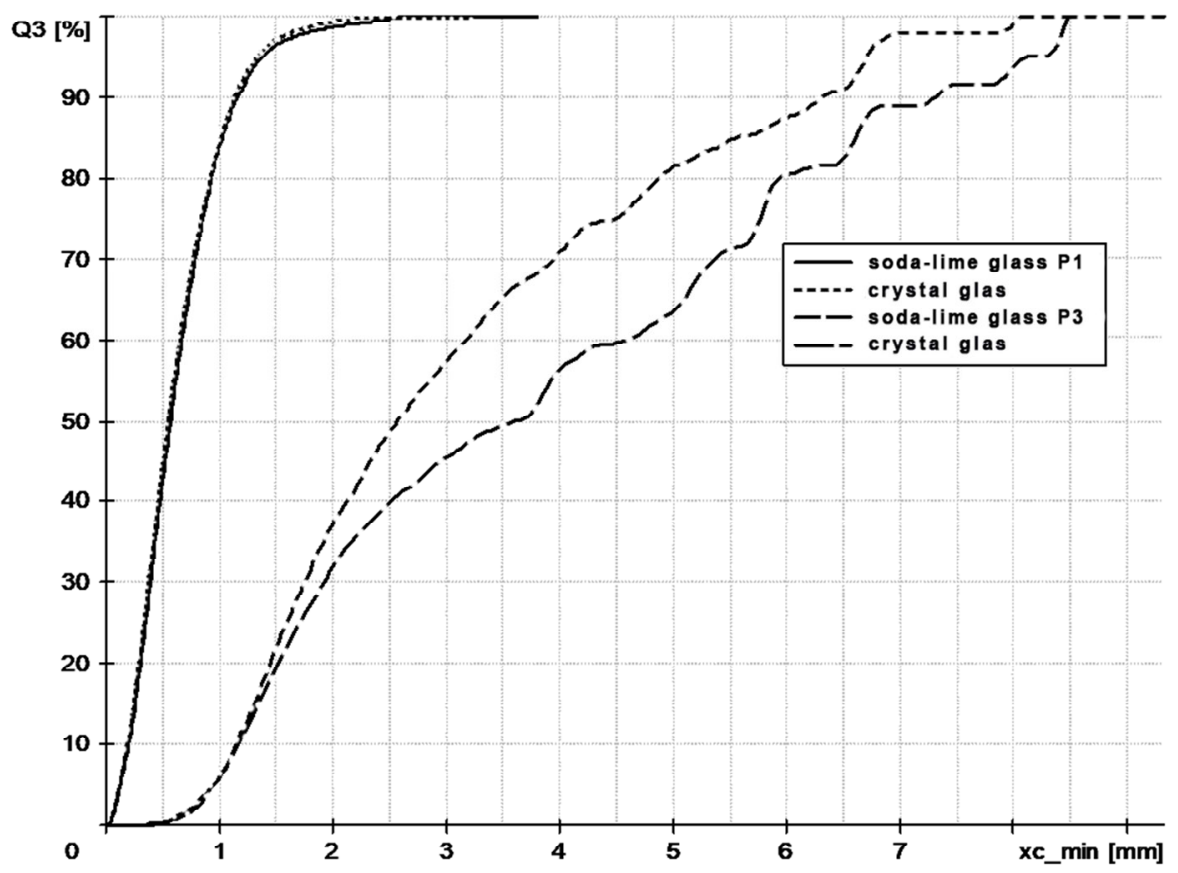

Fig. 1. Cumulative distribution function of soda-lime glass particle size (sample 1-solid line, sample 3-short dashed line), of crystal glass (sample 2-dotted line, sample 4-long dashed line).

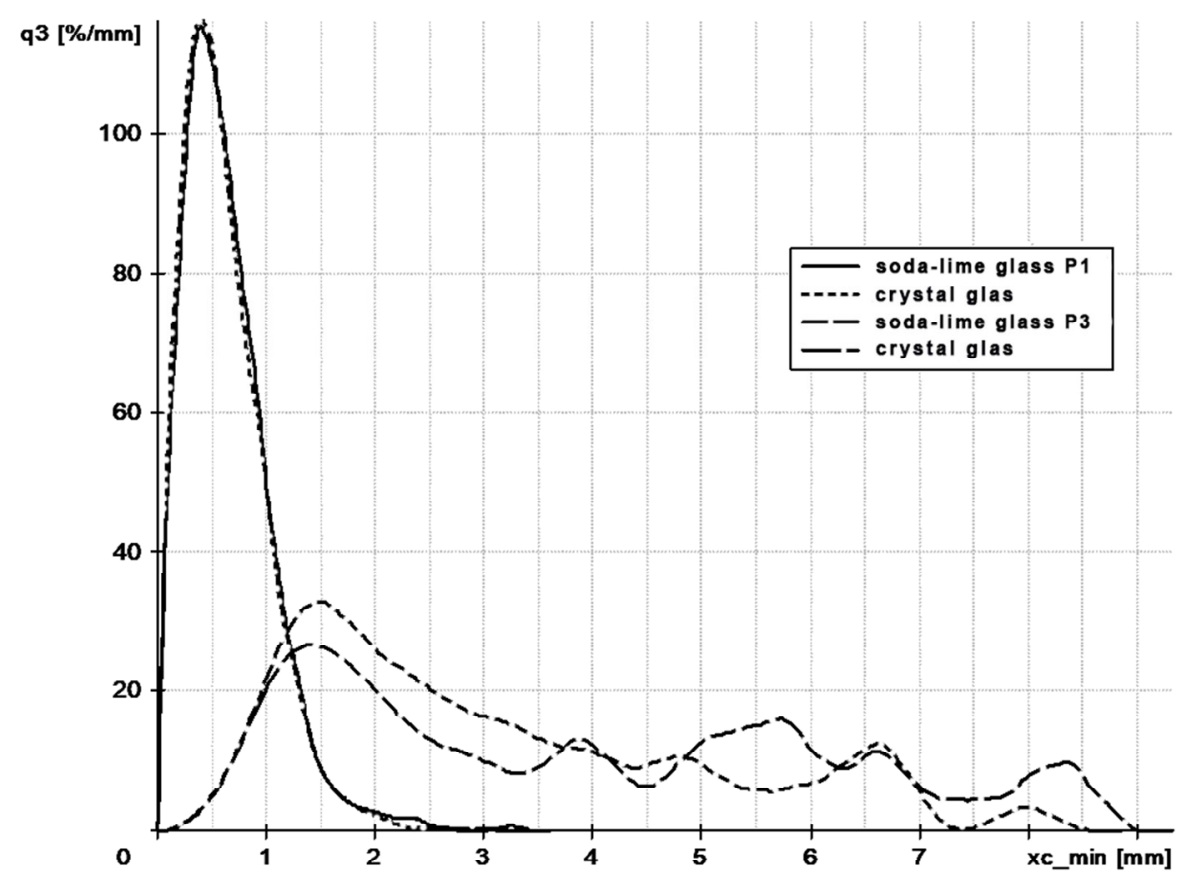

Fig. 2. Particle-size composition of soda-lime glass (sample 1-solid line, sample 3-short dashed line), crystal glass (sample 2-dotted line, sample 4-long dashed line). 
For research a solid ceramic chamber furnace SNOL 4/1200 was used and every kind of test material has been subjected to the heating process. Thermal diagram was shown in Fig 3. The samples used for research at temperatures of $700^{\circ} \mathrm{C}$ and $800^{\circ} \mathrm{C}$ were heated from room temperature to the maximum at the time of 1.5 hours and maintained at this temperature for a period of 1 hour. Tests carried out at temperatures of $950^{\circ} \mathrm{C}$ and $1,000^{\circ} \mathrm{C}$ were heated from room temperature to the maximum in 2 hours and maintained at this temperature for 30 minutes. There was one test made at a temperature of $1,100^{\circ} \mathrm{C}$ that exceeds the melting point of copper. The process of heating started from room temperature and for a period of 2.5 hours maximum temperature was obtained and then maintained for 10 minutes. After the end of the heating time all samples underwent a process of expansion that was freecooling of oven for a period of 24 hours.

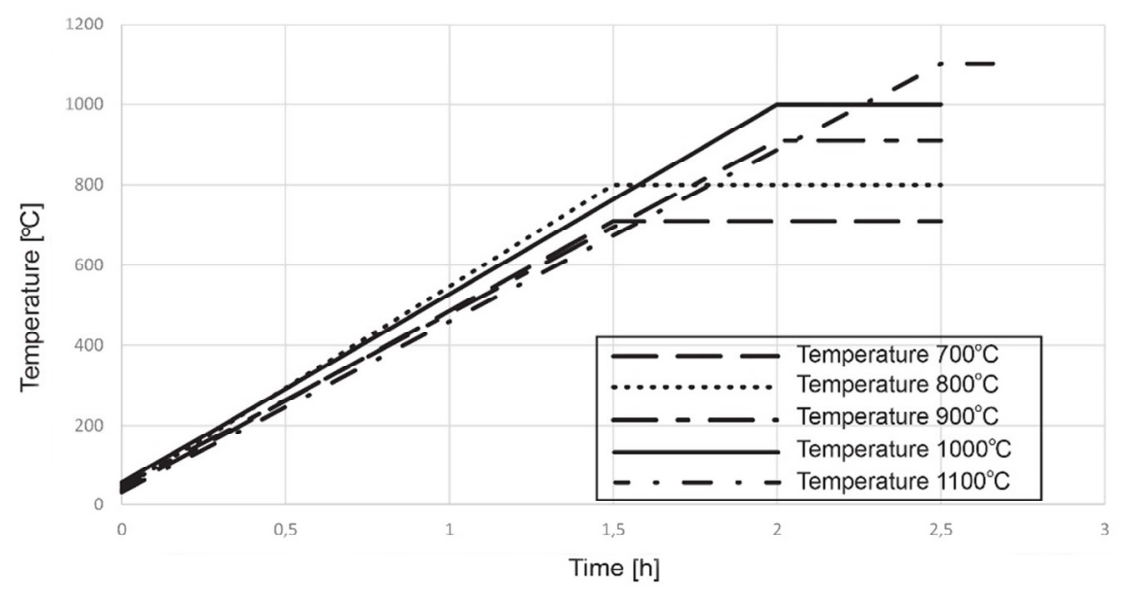

Fig. 3. A temperature graph for the experiments.

Figure $4 \mathrm{a}$ and $4 \mathrm{~b}$ shows the images from the microscope of microsection samples varied in terms of particle size of used glass. Figure 4a shows the glass of $0-1 \mathrm{~mm}$ granulation while figure $4 \mathrm{~b}$ shows the size of the glass above $10 \mathrm{~mm}$. It was observed in the drawing that the material is porous, which can indicate high oxygen content in burnt glass. Figure $4 \mathrm{~b}$ shows a solid structure of glass material after burning with very few errors. Both samples have been prepared under the same conditions.
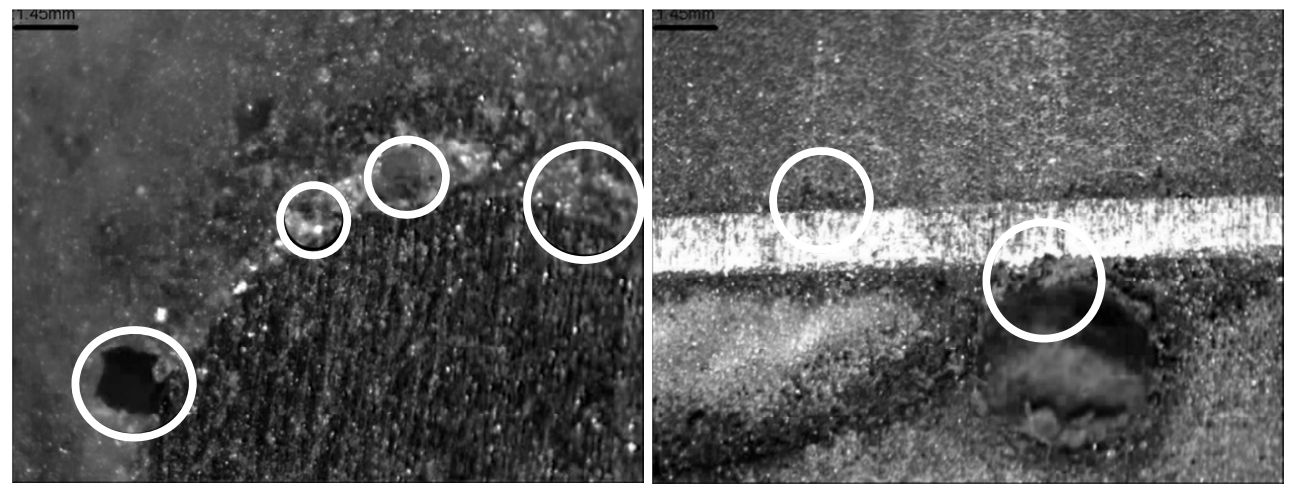

Fig. 4. Photos of samples under microscope: a) glass granulation $0-1 \mathrm{~mm}$, b) glass granulation above $10 \mathrm{~mm}$. 
From the analysis of the temperature research results, differences on the contact surface of glass and metal were observed. Microscope photos for samples containing the granularity of glass material in the range $1-10 \mathrm{~mm}$, baked at different temperatures, were compared. Figure $5 \mathrm{c}$ shows the test taken at a temperature of $1,100^{\circ} \mathrm{C}$, indicated area on the drawing shows a surround created between two materials. In figure $5 \mathrm{~d}$ thickness of the surround is smaller; the test was carried out at a temperature of $900^{\circ} \mathrm{C}$. In Figure 6e the boundary between the materials is flat; test shown in this picture was made at maximum temperature of $700^{\circ} \mathrm{C}$. Area marked in figure $6 \mathrm{f}$ indicates large interaction between materials. The temperature used to test was up to $1,000^{\circ} \mathrm{C}$.
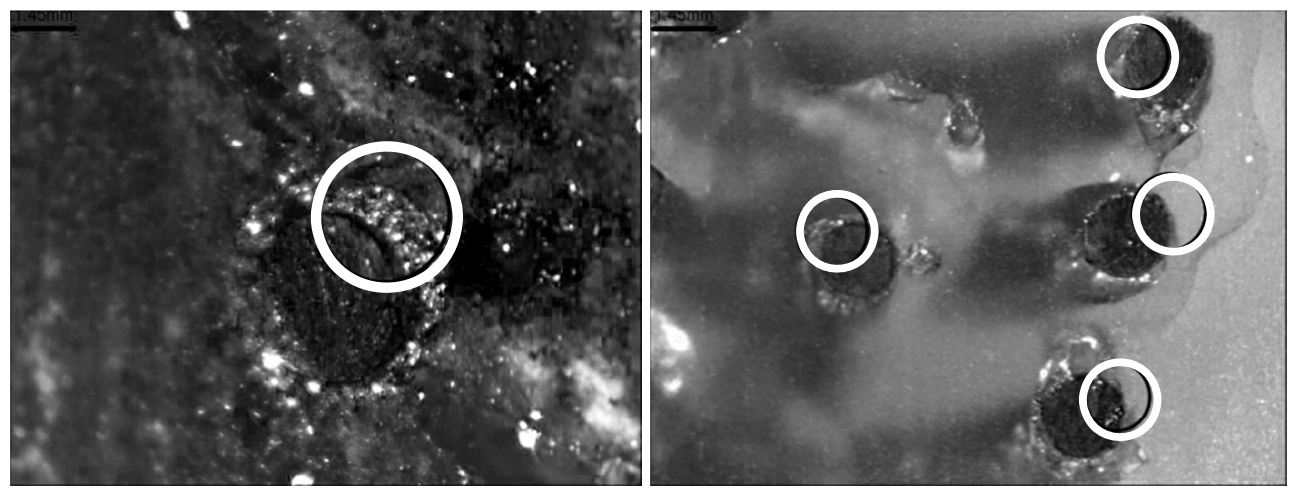

Fig. 5. Photos of samples under microscope: c) test at temperature $1,100^{\circ} \mathrm{C}$, d) test at temperature $900^{\circ} \mathrm{C}$.
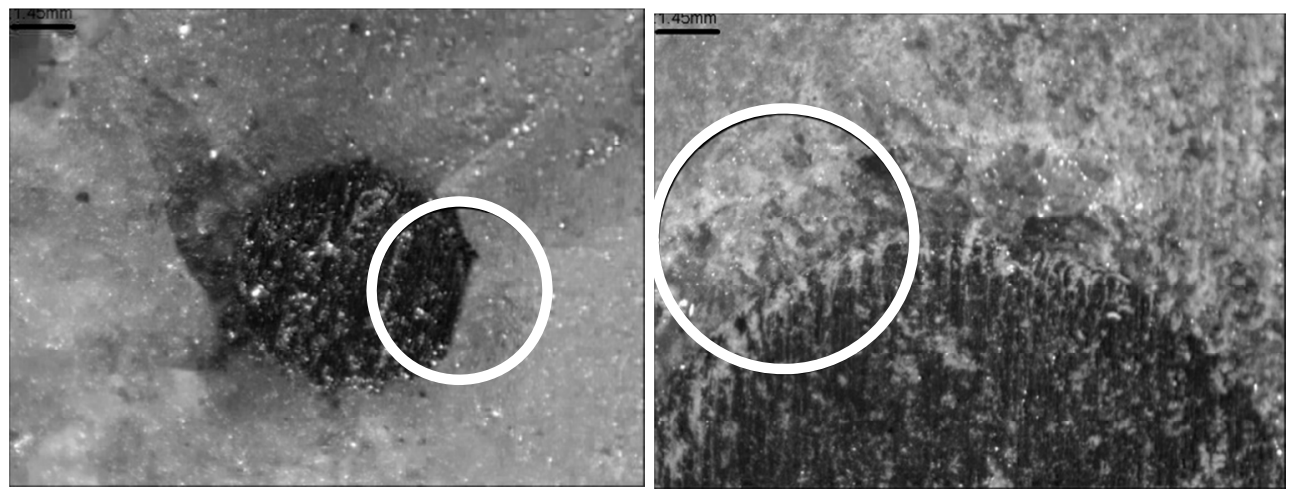

Fig. 6. Photos of samples under microscope: e) test at temperature $800^{\circ} \mathrm{C}$, f) test at temperature $1,000^{\circ} \mathrm{C}$.

Diverse glass material used in the research allowed noticing the difference in behaviour of the cullet baked under the same conditions in the presence of a uniform type of metal component. Samples indicated in the pictures were subjected to baking at a temperature of $1,000^{\circ} \mathrm{C}$. To carry out this test the smallest granule from $0-1 \mathrm{~mm}$ and copper tube was used. Microsection images from the microscope (made along the vertical axis of metal tube) show the difference in the behaviour of various types of glass in the same conditions. Figure $7 \mathrm{~g}$ shows the sample with the use of crystal glass, while in figure $7 \mathrm{~h}$ shows the distribution of soda-lime glass. 

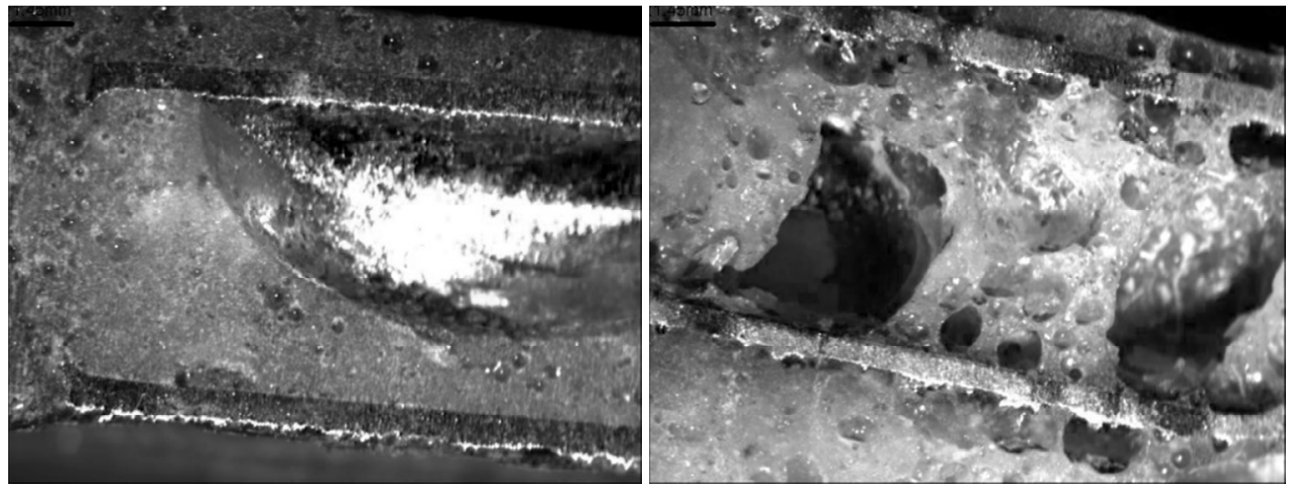

Fig. 7. Photos of samples under microscope: g) test of crystl glass, h) test of soda-lime glass.

\section{Conclusions}

The carried out tests for glass and copper in the form of sheet, tube and rod, depending on the degree of glass breakage, confirmed the possibility of permanent joining of both materials. For the applied glass with granulation $0-1 \mathrm{~mm}$, the structure of the material after the firing process became porous, as a result of which the contact area of the glass with metal was smaller than in the case of glass with a granulation of more than $10 \mathrm{~mm}$. As a result of the research, it was noticed that the glass whose degree of fragmentation was in the range from 0 to $1 \mathrm{~mm}$ after melting in the oven lost its transparency, obtained a matte structure, which may indicate the impossibility of air escape during the smelting process. Increasing the size of the glass grains resulted in increased transparency of the glass material. The heating time of glass and copper and the soaking time at the set temperature of $1,100^{\circ} \mathrm{C}$ had the most beneficial effect on the obtained structure of joining both materials. The temperature obtained has exceeded the melting temperature of copper by $17^{\circ} \mathrm{C}$. Exceeding the melting temperature of the metal gives the opportunity to continue the research towards the connections of glass with metal with a changing state of focus. As a result of the microscopic analysis, it can be concluded that there is a permanent connection between glass and copper. This connection is the result of adhesion forces. The tests showed a difference in the behavior of the glass in the temperature range used. Crystal glass, baked at a temperature above $900^{\circ} \mathrm{C}$, had scratches and cracks in the area of contact with copper as well as in the whole body. Higher temperatures were optimal for the cooperation of soda-lime glass with metal.

\section{References}

1. A. Wyrobisz, (Szkło w Polsce od XIV do XVII wieku, Wydawnictwo PAN, 1968)

2. A. Polak, (Szkło i jego historia, Wydawnictwo Naukowe PWN, 1981)

3. http://sztuka-architektury.pl/article/2992/szklo-w-architekturze, (downloading date 05.04.2018)

4. http://www.sztuka-wnetrza.pl/3836/artykul/kolorowe-szklo-w-aranzacji-wnetrz, (downloading date 05.04.2018)

5. http://www.wiecejnizzdrowie.pl/chromoterapia-leczenie-kolorem/ (downloading date 05.04.2018)

6. M. J. Terro, Build. Environ., 41, 633-639 (2006)

7. E. E. Ali, S. H. Al-Tersawy, Constr. Build. Mater., 35, 785-791 (2012) 
8. A. Mohajerani, J. Vajna, Tsz Ho Homan Cheung, H. Kurmus, A. Arulrajah, S. Horpibulsuk, Constr. Build. Mater., 156, 443-467 (2017)

9. D. Raut, R. L. Narayan, P. Tandaiya, U. Ramamurty, Acta Mater., 144, 325-336 (2018)

10. A. Mirza, M. Riaz, R. Zia, T. Hussain, F. Bashir, J. Alloys Compd.,726 348-351 (2017)

11. M. Wirwicki, T. Topolinski, Zirconium dioxide - static test on glued connections, Engineering Mechanics, 724-727, (2014)

12. I. Płoński. (red.), (Technologia szkła, Arkady, Warszawa 1962) 